\title{
Study on SGD in the Coastal Zone of the Huanghai and Bohai: A review
}

\author{
jinming zhang ${ }^{1}$, Jun Kong ${ }^{2}$, Ziwen Zhou ${ }^{1}$, Xiaosong Dong ${ }^{1}$, and Canhao Cai ${ }^{1}$ \\ ${ }^{1}$ Hohai University \\ ${ }^{2}$ State Key Laboratory of Hydrology-Water Resources and Hydraulic Engineering
}

August 28, 2020

\begin{abstract}
In recent years, hydrogeologists have paid more and more attention to the discharge of submarine groundwater(SGD), which is a typical and important process of the interaction between seawater and groundwater in coastal areas, tidal flats and estuaries. As an important sources of water and chemical materials to ocean, SGD affects the global water cycle and coastal ecological environment. SGD also influence the transport path of pollutants from land to the sea. Therefore, it affects the local and global circulation of coastal groundwater and seawater. Since it usually occurs in aquifer, it is easily overlooked by the researchers. In addition, due to the uncertainty of SGD in time and space, it is difficult to be measured accurately. Aiming at recently study, this paper will discuss the research process, research method, research field and environmental significance of SGD on the coast of the Huanghai and the Bohai. Based on the analysis of the existing research results, some suggestions on improving SGD investigation are put forward.
\end{abstract}

\section{Introduction}

SGD is defined as any and all flows of water from the seabed to the coastal continental margin, regardless of fluid composition and driving force (Burnett et al. , 2003). SGD was discovered and used in undersea springs before the 20th century. However, it was not until the 1980s that scientists began to pay attention to SGD because it also made a difference to groundwater emissions in coastal waters (Burnettet al. , 2003). SGD is an important part of the global water cycle and an access for land to transfer water and materials to the ocean. It affects the ecological environment of coastal areas. Excessive nutrients and other substances carried by SGD are discharged into the coastal waters, which will produce man-made interference to the biogeochemical process in the coastal zone, causing serious damage to mariculture, fishing and other marine economic activities(Kim et al. , 2005; Swarzenski et al. , 2007; Hwang et al. , 2010). SGD has been studied along different coast including sandy, bedrock fissure and karst coast, of which Many research sites are located in the east and west coasts of the United States in North America (Moore, 1996, 2007, 2010; Zarnoch et al. , 2017; Adolf et al. , 2019; Kelly et al. , 2019), and the eastern coastal areas of Brazil in South America(Niencheski and Windom, 2015; Dias et al. , 2016; da Rochaet al. , 2018), the Mediterranean coast of Europe (Aaron et al., 2019; Oehler et al., 2019; Tamborski et al., 2018,2019) and the Baltic coast (Donis et al. , 2017; Krall et al. , 2017; Franzet al. , 2019), The east and west coast of Australia (Lamontagne and Webster, 2019; Maher et al. , 2019; Sadat-Noori and Glamore, 2019), South Korea , Asia (Lee et al. , 2018; Cho et al. , 2019; Kang et al. , 2019) and the coast of Japan (Burnett et al. , 2018; Nikpeyman et al. , 2019; Zhu et al. , 2019).

In recently years, the study of SGD along Chinese coastal arose people's attention. The coastline in China is about 18000 kilometers long, which is one of the longest countries in the world. The research focuses on the 
uneven distribution of groundwater input in Jiaozhou Bay, Laizhou Bay and Tolo Bay ((Cen et al. , 2017; Liu et al. , 2018; Yuan et al. , 2018). There exsists a wide and thick distribution area of loose sediments in the estuary of Yellow River, Yangtze River, Pearl River and other rivers. In addition, the water yield of coastal aquifer is good, resulting in the large amount of groundwater input(Xuet al. , 2014; Xia et al. , 2016; Guo et al. , 2017; Liu et al. , 2018). In the east coast of Hainan Island, groundwater input pose a huge impact on the local environment (Wang and $\mathrm{Du}, 2016$ ), while the input of groundwater in the Minjiang River estuary is very limited (Liu et al. , 2016). However, due to the difficulties in field investigation or research, the requiry of the cooperation of scholars in ocean dynamics, groundwater dynamics, ocean and groundwater geochemistry, isotopic chemistry, etc. the research on SGD in China lags behind such countries and regions, which is seriously divorced from the increasingly serious environmental pollution and ecological deterioration in China's near sea.

The Bohai Sea and the Yellow Sea are important sea areas in the north of China, whose coastlines account for about one third of the total length of China's (Figure 1). The coast there is one of the most active areas of economic and social activities. There are Liaodong Bay, Bohai Bay, Laizhou Bay, Jiaozhou Bay and other bays along the coast of the Yellow Sea and the Bohai Sea, as well as six provinces and cities of Liaoning, Hebei, Tianjin, Beijing, Shandong and Jiangsu. These provinces and cities have superior geographical location and are the main industrial and residential areas. In addition, the Yellow Sea and the Bohai Sea are important sea areas in China, and as the junction of land and marine ecosystem, they are one of the most rich-biodiversity regions in the world, which can meet the needs of human's life and development. Therefore, the coastal zone of the Yellow Sea and the Bohai Sea has also become the most densely populated and economically developed area in the world. In today's economic globalization, the region also plays an increasingly important role. However, with the development of industry, agriculture and the enhancement of human activities, more land-based pollutants are generated. The pollutants and nutrients contained in SGD can be several times of magnitude higher than surface runoff (Charetteet al. , 2001; Slomp and Van Cappellen, 2004). For example, according to the research, along the Yellow Sea and Bohai Sea, the SGD value of Laizhou Bay is $4.12^{*} 10^{7} \mathrm{~m}^{3} / \mathrm{d}$ (Wang et al. , 2015), and that of Jiaozhou Bay is $1.21^{*} 10^{7} \mathrm{~m}^{3} / \mathrm{d}$ (Zhang et al. , 2017). To some extent, SGD may cause the deterioration of the marine environment such as the highly eutrophic of coastal water and red tide. In order to understand the process of SGD, this paper introduces this important land sea interaction process with the case study of the Yellow Sea and the Bohai Sea.

This study first describes the formation process of SGD and then introduces the common investigation methods of SGD. The basic purpose is to summarize the research situation of SGD along the Bohai Sea and the Yellow Sea, analyze the environmental impact of SGD on the coastal areas and provide suggestions for further research on SGD in the future.

\section{The Classification and Process of SGD}

Due to the dual effects of land and ocean driving forces, it includes two components namely the pure supply from the inland (generally fresh water) and the circulation of sea water (that is, the water flowing back to the ocean after entering the offshore aquifer through the sea land interface under the action of sea tide, wave, density difference of saltwater and fresh water and other factors (Figure 2). Thus, SGD can be divided into SFGD and SRGD (Figure 2).

SFGD is the groundwater formed by the infiltration of atmospheric precipitation, which comes from the mainland and consists of phreatic water and confined water. The SFGD has experienced sufficiently water rock interaction before its infiltration into the sea. So, with a large number of soluble substances dissolved in the underground water, its material composition mainly comes from the dissolution and filtration of soil, sediment and rock. The driving force of SFGD is local hydraulic gradient. Since the ground water level on the land is higher than the sea level, the head difference drives the ground water in the aquifer on the land to discharge to the seafloor (Burnett et al. , 2003; Moore, 2010; Santos et al. , 2012; Li and Jiao, 2013). 
The deep confined aquifers in some coastal areas can extend far to the bottom of the sea, which means that the land-based underground fresh water can discharge far away from the shore.

SRGD comes from seawater and returns to seawater. The driving forces are mainly tidal pump, wave action and density difference (Burnett et al. , 2003; Moore, 2010; Santos et al. , 2012; Li and Jiao, 2013). When the tide is rising, the upward seawater under the action of tide pump seeps into the aquifer and becomes underground water. It seeps out from the aquifer and returns to the ocean when the tide is ebbing. The circulating sea water under the action of wave mainly occurs along the sandy beach. Compared with the action of tide pump, its circulating depth is much smaller, but its circulating frequency is much higher, which is shown as follows rapid replacement of pore water in surface sediments. The circulating seawater driven by density difference occurs under the mixed zone of saltwater and fresh water in the coastal aquifer. A salt wedge is usually formed in the aquifer, as the density of seawater is higher than that of fresh groundwater (Robinson et al. , 2007).

Besides the flow exchange between surface and subsurface water, circulating seawater and land-based underground both form a net dissolved matter input to the ocean, increasing the amount and types of dissolved substances in the seawater (Dzhamalov and Safronova, 2002). When the sea water seeps into the aquifer, it not only mixes and reacts with the ground fresh water, but also dissolves the soluble substances in the aquifer rock and soil. Therefore, the significance of circulating seawater in aquifer mainly reflected by its geochemical cycle and landy material input.

\section{Common Methods on SGD Accessment}

In recent years, there are many methods on SGD detection and estimation. Presently, the commonly used SGD evaluation methods can be sumarized into four categories: direct measurement method, hydrological model method, environmental isotope tracer method and geophysical tracer method.

\section{Direct measurement}

This method is to measure SGD directly by means of percolator. In 1977, Lee (Lee, 1977)invented the manual percolation instrument. Its structure is very simple, mainly composed of a stainless steel cylinder with a volume of $208 \mathrm{~L}$ and one end closed, a conduit with a double valve switch and a water collecting bag with a volume of $4 \mathrm{~L}$. At present, the more advanced automatic percolator is based on thermal pulse technology (Taniguchi et al. , 2003), acoustic doppler technology or dye dilution technology(Sholkovitz et al. , 2003). It can record the change of groundwater discharge with the tide cycle continuously. However, it costs a lot of time and labors to measure SGD with the percolator, as it requires the diver to place and recover the percolator on the seabed. Moreover, the percolator can only measure the local SGD. When necessary to make out the characteristics and laws of the regional SGD, a large number of measuring points must be arranged. In addition, the measurement process of seepage meter is easily disturbed or damaged by current and wave (Cable et al. , 1997). To a certain extent, these drawbacks prevent percolator from widely use.

\section{Hydrological model}

It refers to calculate groundwater discharge by hydrogeological mathematical methods to evaluate SGD, based on Darcy's law, water balance method and numerical simulation method.

Darcy's law realizes the leap from the qualitative and semi qualitative analysis to the quantitative evaluation of groundwater, which is the basis of the assessment of groundwater. It is used to calculate the amount of groundwater flowing through the aquifer driven by the hydraulic gradient (Ma et al. , 2015; Qu et al. , 2017). 
Meanwhile the theoretical basis of water balance method is necessary that the expenses and receipts of water in a certain region or even in the whole world is balanced, of which SGD is a part. If we know other items, we can get the amount of SGD according to the balance formula (Burnett et al. , 2003). However, the reliability of water balance method depends on the variable precision of each hydrological process, such as precipitation, evaporation, surface runoff and artificial exploitation. The evaporation is especially difficult to estimate, leading to the error which can not be overlooked.

The numerical simulation method is using the finite element method or the finite difference method to discretize the flow equation and solute transport equation spatio-temporal, and to get the flow velocity and salinity on the discrete element. The groundwater discharge can be calculated according to the seepage velocity distribution on the aquifer boundary (Chang et al. , 2018; Yu et al. , 2019). However, at present, the problems faced by this model are: serious lack of hydrogeology data; inappropriate generalization of parameters; simplification of complicated driving force from the ocean et al. Since so, the simulated results usually deviate much from the total discharge of groundwater evaluated by seepage mete, tracer method and measured (Oberdorfer, 2003; Moore, 2010).

\section{Environmental isotope tracer}

Geochemical tracing uses natural radionuclides of uranium and thorium decay series. These natural radionuclides usually have higher concentration in groundwater with lower reactivity in coastal seawater, which means chemical behavior is more conservative. The basic theory of using tracer to evaluate groundwater discharge is the mass balance principle (Yuan et al. , 2016; Zhang et al. , 2016). The tracer technology combined the SGD signals in the coastal waters effectively and ignored the heterogeneity of groundwater discharge. The results show the average level of SGD on a regional scale (Burnettet al. , 2001).

\section{Geophysical tracing}

The resistivity measurement technology based on the electrical difference between salt and fresh water body and surrounding soil is a new monitoring method developed in the early 21st century. Compared with other methods, resistivity method has the advantages of continuity, spaciality and intuitionistic mapping. It can be used not only for local monitoring, but also for large-scale detection. In its initial stage, it is often used as a comparison method, which is often combined with temperature sensing and tracer method to monitor the groundwater discharge process (Henderson et al. , 2010). With the development by Henderson, Dimova and Johnson (Henderson et al. , 2010; Johnsonet al. ,2015), resistivity method gradually shows its technical advantages and application potential in the aspects of real-time reflection of water transport, identification of conversion interface, estimation of local discharge, etc., and has been applied more and more. However, from the current application examples, this method is also mainly used for the discharge monitoring of the phreatic aquifer in the tidal process.

\section{SGD Investigation Along Huanghai and Bohai}

Globally, the earliest SGD research on the Yellow Sea and Bohai Sea was carried out at the mouth of the Yellow River (Taniguchi et al. , 2008). They found that since 1990, a shortage of irrigation water had often cut off the lower reaches of the Yellow River, and conducted the study using direct observations to assess the impact on the Yellow River delta. They observed two different sections during 2004-2006 and calculated that SFGD per unit length coastline was $110 \mathrm{~m}^{3} / \mathrm{s}$ in 2004 and $170 \mathrm{~m}^{3} / \mathrm{s}$ in 2006 , which was equivalent to $4.5 \%$ to $7.0 \%$ of the Yellow River flow during the same period. During these three years, the largest SGD zone moved $2 \mathrm{~km}$ offshore from September 2004 to September 2006 due to coastal sediment deposition. In addition, they demonstrated a hydraulic link between surface and pore water under the seabed. However, this approach is limited by the amount of data. 


\section{SGD studies in Bohai Bay}

(Liu et al. , 2017a; Yi et al. , 2019) both used radium isotope tracer in Bohai Sea area to study SGD. Lixin Yi studied the effects of geological lithology, human activity, terrestrial groundwater activity, SGD flux rate, mixing process and geochemical environment (salinity) on ${ }^{223} \mathrm{Ra},{ }^{224} \mathrm{Ra}$ and ${ }^{228} \mathrm{Ra}$ in different water bodies, demonstrating that the relative level of isotopic activity in coastal groundwater and coastal seawater is determined by the interaction between groundwater and seawater. Jianan Liu used the mass balance model of ${ }^{226} \mathrm{Ra}$ and ${ }^{228} \mathrm{Ra}$ to calculate that SRGD had a much greater impact on Bohai Sea than SFGD. The value of SGD he calculated was $(2.0 \pm 1.3) \times 10^{11} \mathrm{~m}^{3} / \mathrm{yr}$.

\section{SGD in Huang River estuary}

(Xu et al. , 2013) conducted a study using ${ }^{223} \mathrm{Ra},{ }^{224} \mathrm{Ra}$ and ${ }^{226} \mathrm{Ra}$. He calculated that the SGD flux was $1.3^{*} 10^{9} \mathrm{~m}^{3} / \mathrm{d}$, and the range of variation was $2.8^{*} 10^{8}$ to $3.0^{*} 10^{9} \mathrm{~m}^{3} / \mathrm{d}$. Moreover, he believed that the SGD flux had little impact on sediment generation. (Taniguchiet al. , 2008)mainly investigated SFGD with an automatic percolation apparatus. In September 2004 and September 2006, the SFGD of the whole delta was about 110 and $170 \mathrm{~m}^{3} / \mathrm{s}$, respectively. These freshwater flows are equivalent to 4.5 to 7.0 per cent of the Yellow River's flow over the same period. Both scholars noticed the migration of SGD region.

In 2014, (Xu et al. , 2014) first studied the impact of Water Sediment Regulation Scheme (WSRS) on SGD. They used the field measurements from ${ }^{222} \mathrm{Rn}$ and ${ }^{220} \mathrm{Rn}$ to determine the possible SGD location of the Yellow River estuary and concluded that high river flow $\left(>3000 \mathrm{~m}^{3} / \mathrm{s}\right)$ may be necessary for a large amount of fresh SGD in the system. They also observed that during the WSRS, FSGD resulted in a unique vertical profile of the benthic boundary layer, with a decrease in all salinity, dissolved oxygen, and turbidity. Futher more, they built a positive correlation between nutrient content and ${ }^{222} \mathrm{Rn}$, indicating that SGD is the main nutrient route in the estuary of the Yellow River.

(Xia et al. , 2016) integrated other hydrological parameters in space and time for radium and radon isotopes during the non-WSRS and WSRS in 2013. By comparing the data, it can be seen that the radium $\left({ }^{223} \mathrm{Ra}\right.$, ${ }^{224} \mathrm{Ra},{ }^{226} \mathrm{Ra}$ ) and ${ }^{222} \mathrm{Rn}$ activities in the Yellow River estuary during the WSRS period are significantly higher than those in the non-WSRS period. This different distribution may predict the changes of fluid dynamics and SGD flux. The artificial flooding caused by WSRS accelerates the hydrodynamic process and increases the offshore transport rate. It is found that the SGD flux of the Yellow River estuary during WSRS is much larger than that during non-WSRS. During the WSRS, SGD was highest along the channel, and the composition of fresh SGD was conservatively estimated to account for about $24 \%$ of the total SGD.

\section{SGD studies in Laizhou Bay}

\section{SGD investigation in the eastern coast}

In the eastern part of Laizhou Bay, (Xing et al. , 2016) detects potential SGD by analyzing the seawater surface temperature anomaly obtained from the maximum temperature difference between seawater and groundwater in the thermal image. The results show that when the tide fluctuates between $0.5-1.8 \mathrm{~m}$, the temperature changes from 13.8 to 23.3 , and the salinity from 17.91 to 33.27 the anomaly of sea surface temperature is not related to long coastal circulation or river flow, so it may be related to local SGD.

Recently, (Zhang et al. , 2016) used ${ }^{222} \mathrm{Rn}$ to evaluate SGD on the east coast of Laizhou Bay. Based on the ${ }^{222} \mathrm{Rn}$ mass balance model and continuous monitoring, the flux of SGD was $6.64 \mathrm{~cm}^{3} / \mathrm{d}$ to $7.21 \mathrm{~cm}^{3} / \mathrm{d}$, with an average of $6.93 \mathrm{~cm}^{3} / \mathrm{d}$, which was consistent with the results of other scholars and numerical simulation. Subsequently, this paper estimated the impact of SGD on local environment. The estimated DIN, TDN and TDP were $7.79^{*} 10^{6} \mathrm{~mol} / \mathrm{d}, 8.92^{*} 10^{6} \mathrm{~mol} / \mathrm{d}$ and $1.41^{*} 10^{4} \mathrm{~mol} / \mathrm{d}$, respectively, which were equal to or even 
higher than the Yellow River. In addition, this study shows that tides play an important role in SGD variation. The concentration of ${ }^{222} \mathrm{Rn}$ is greatly affected by tides and fluctuates at high tide and low tide, respectively. Moreover, flux and sediment diffusion of ${ }^{226} \mathrm{Ra}$ are independent of the total SGD supply.

Although there are few studies on the east coast of Laizhou Bay and the data are severely limited, the results have theoretical and practical significance for the effective management of vulnerable water resources in Laizhou Bay. Based on an understanding of hydrogeological processes, more work and knowledge on the cycle between groundwater and seawater in coastal areas is required to achieve sustainable development and management.

\section{SGD investigation in the northwest coast}

On the northwest coast of Laizhou Bay, (Ma et al. , 2015)studied the SGD exchange rate of a tidal flat with a large-scale seepage surface. Under Darcy's law and taking full account of the density variation, the SGD quantity and inflow quantity here are respectively $8.8 \mathrm{~m}^{3 *} \mathrm{~d}^{-1 *} \mathrm{~m}^{-1}$ and $15.3 \mathrm{~m}^{3} * \mathrm{~d}^{-1 *} \mathrm{~m}^{-1}$. Due to the large seepage surface area, low sediment permeability and very gentle slope, the outflow showed a trend of first decreasing and then increasing, while the inflow first increased and then decreased, which is obviously different from the sandy or gravel beach.

\section{SGD investigation in the southern coast}

On the southern bank of Laizhou Bay, (Hou et al. , 2016) found the silty tidal flat. They found that the salinity here was 25 to $56 \mathrm{~g} / \mathrm{L}$. The value of SGD and inflows are $164.0 \mathrm{~m}^{2} / \mathrm{d}$ and $6.5 \mathrm{~m}^{2} / \mathrm{d}$. Later, more and more scholars have carried out a lot of researches in the south coast of Laizhou Bay, as SGD here is typical and it has a great impact on the coastal environment. Considering the process of groundwater discharge in the intertidal zone, this area is further studied using numerical simulation, field monitoring, electrical conductivity and other methods. (Han et al. , 2014)also studied the hydrochemistry and hydrogeology of the area.

In general, the study results on the southern shore of Laizhou bay can be sumariezed as follows :(1) groundwater farther from the sea is more resupplied from inland sources. (2) Salinity is mainly affected by two factors. On one hand, intense evaporation leads to a continuous accumulation of salt on the beach surface. On the other hand, the brine is extracted and seeped during inland salt leaching, which will also increase the salinity of groundwater. (3) SGD was caused by the existence of seepage surface in intertidal section due to the low permeability coefficient and gentle slope of the intertidal zone. In the intertidal zone from the inland to the ocean, relatively high water heads allow groundwater to drain to the surface. (4) The dynamics of the submarine groundwater in Laizhou Bay is affected by precipitation and tide, and has a periodic variation pattern. (5) The seabed groundwater in Laizhou Bay is stratified, which can be divided into five layers, roughly the same as the sedimentary strata, and is mainly affected by the distribution of brine aquifers formed in three transgression periods since the late Pleistocene. (6) Large amount of water flow is the effect of large amount of underground water flow driven by density. The gradual lowering of salinity to the sea may be due to evaporation, human activities such as the extraction of subsurface brines and the construction of many projects, and the discharge of inland freshwater near low-tide zones.

\section{SGD studies in Jiaozhou Bay}

In Jiaozhou Bay, (Wang et al. , 2014) studied the distribution characteristics of radium isotopes in water bodies to prove that the activity of ${ }^{224} \mathrm{Ra}$ and ${ }^{226} \mathrm{Ra}$ may be influenced by local lithology, human activities and groundwater recharge. In addition, the activity distribution of ${ }^{224} \mathrm{Ra}$ in Jiaozhou Bay decreased gradually with the increase of offshore distance, while the activity of ${ }^{226} \mathrm{Ra}$ remained at a high level in the whole jiaozhou Bay, which provided the basis for the follow-up study. 
(Yuan et al. , 2016) estimated SGD flux by using the mass balance method of ${ }^{226}$ Ra. The discharge flux of submarine groundwater in Jiaozhou Bay from September to October in 2011 was $7.85^{*} 106 \mathrm{~m}^{3} / \mathrm{d}$, while that in Jiaozhou Bay from April to May in 2012 was $4.72 * 106 \mathrm{~m}^{3} / \mathrm{d}$. Yan Zhang (2017) improved this model by fully taking the tracer loss in seawater caused by RSGD into account, especially when the concentration difference between offshore seawater and groundwater is not large enough. The result is $1.21^{*} 10^{7}$ to $2.17^{*} 10^{7} \mathrm{~m}^{3} / \mathrm{d}$, which is $1.34^{\sim} 1.44$ times of the previous model.

In 2017, (Qu et al. , 2017)used generalized darcy's law to describe the cross section flow dynamics, seawater exchange rate of groundwater, SGD related nutrient flux and nutrient flux (DIN and DIP) of four different wetland types. He calculateed the SGD exchange rate was $3.6^{*} 10^{-3}$ to $7.6 \mathrm{~cm} / \mathrm{d}$, which reached the maximum in the sandy coastal zone. This phenomenon proves that the rate of SGD has good correlation with hydraulic conductivity. In addition, (Yuanet al. , 2018) studied the influence of SFGD on the seasonal and spatial variation, distribution and flux of dissolved and granular nutrients in Jiaozhou Bay, proving its important role in the ecosystem of Jiaozhou Bay.

Furthermore, (Yang et al. , 2013) proposed a biogeochemical model and a new definition of marine bay water exchange time. He used the ratio of non-conservative substance $\mathrm{Si}$ and $\mathrm{N}$ as tracer of water in the bay. According to the definition of water exchange completed in the Bay and the filling and empting principle of the bay, he calculated that the water exchange time of Jiaozhou Bay was between 12 and 15 days, and the average value was 12.5 days. This method does not need to be based on the dynamics of power flow, and it is not affected by power flow parameters and variables. Therefore, as long as the new definition, principle, method and biogeochemical model are used to study the water exchange capacity of Jiaozhou Bay, the water exchange time of Jiaozhou Bay can be calculated. The results obtained are basically similar to those calculated by box model and numerical model by State Oceanic Administration and Qingdao Aquatic Products Administration (1998).

\section{SGD in Huanghai}

In 2016, (Liu et al. , 2017b) used the ${ }^{228}$ Ra mass balance method to investigate SGD flux on the south coast of the Yellow Sea. As a semi-closed sea area, the SGD input of yellow Sea is $(1.3+-1.0)^{*} 10^{12} \mathrm{~m}^{3} / \mathrm{yr}$, which is $5.9+-3.9$ times of the total inflow of other rivers. In the southern part of the Yellow Sea, SGD also had a huge impact on the environment. Its DIN, DIP and DSi were $(487+-384) \times 10^{9} \mathrm{~mol} / \mathrm{yr},(2.8+-2.2) \times 10^{9}$ $\mathrm{mol} / \mathrm{yr}$ and $(313+-259) \times 10^{9} \mathrm{~mol} / \mathrm{yr}$, respectively, which were considered by scholars as important factors for the outbreak of cyanobacteria in the Yellow Sea.

\section{Finally Remark}

The compilation of studies in the Bohai Sea shows that the flux of SGD has been analyzed and calculated in all the five regions, and it is proved that the input of SGD is much larger than the total inflow of each river. In addition, in some areas, the impact of SGD on the environment was also considered. They investigated that the N/P ratio of SGD input was higher than that of river input and the utilization ratio of $\mathrm{N}$ and $\mathrm{P}$ of phytoplankton in coastal zones. If $\mathrm{N}$ and $\mathrm{P}$ are added to coastal waters through $\mathrm{SGD}$, the original $\mathrm{N} / \mathrm{P}$ ratio and $\mathrm{N}$ as restrictive nutrient elements in coastal waters will be gradually changed, which not only directly leads to eutrophication and phytoplankton explosive reproduction, but also may change the population structure of phytoplankton in coastal waters.

However, we have noticed that there are still a lot of areas that have not been studied along the coast of the Bohai Sea such as the coastal areas of Jiangsu province, Tianjin province, Hebei province, Dalian City and Jinzhou City in Liaoning province. This indicates that in the future, we should focus on promoting SGD research in the direction of distribution and scale. 
In recent ten years, although great progress has been made in SGD research in the Yellow Sea and Bohai Sea area, some problems have not been solved well

Strengthen the study of biogeochemical cycle in underground estuaries. Because of the wide range and variation in the concentration of nutrients, carbon, and metals in aquifers, it is necessary to understand the major controlling factors for these components in coastal aquifers and the chemical reactions that may occur in the concentration of these components along the SGD flow path from land to ocean. The greatest difficulty in the study of underground estuaries is the stratified sampling of groundwater at different depths. There are usually few wells available in the coastal zone. Although there are many fixed wells, they are unable to meet geochemical cycling studies owing to small pore water samplers do not reach the desired depth.

In the Bohai and Huanghai area, the influence of SGD on carbon cycle should be strengthened. In the biosphere of the global carbon cycle, carbon is mainly distributed on land, sea and atmosphere. Relative to the surface water, groundwater of total dissolved inorganic carbon (DIC), the content of CO2 and CH4 is higher. Moore used Ra flux in groundwater, the ratio of DIC/Ra and DOC/Ra to evaluate DIC and DOC (total dissolved organic carbon) input by SGD. The results showed that the flux is greater than quantitative determine SGD freshwater rivers carry input component quantitative evaluation of the new method and means. Therefore, it is very important to study the effect of SGD on the carbon cycle along the Coast of The Bohai Sea and the Yellow Sea.

The comprehensive influence of sea level fluctuation and human activities on the large-scale hydrogeological system of coastal zone should be studied. SGD in coastal aquifers is affected by sea level rise, groundwater exploitation, dredging of ports, changes of coastline and other factors. However, the comprehensive effects of these factors on coastal aquifers and SGD have not been fully studied. In addition, studies on the Yellow Sea and Bohai Sea region mainly focus on important river mouth areas and small scale bays, and there are few large-scale SGD studies, which makes the understanding of SGD insufficient.

Study the hydrogeological conditions of the coastal zone and different types of coastal zone. In the region of Bohai Sea and Yellow Sea, the research focuses on the sandy coast, and the research on other types of coast is less. In addition, the subsurface flow conditions have not been fully described and quantitative analysis, which makes the traditional methods have many shortcomings. In the process of SGD investigation, it is necessary to have a sufficient understanding of the coastal hydrogeological conditions, which is of great significance to distinguish SFGD and SRGD.

In order to describe SGD in more details in the Yellow and Bohai Sea region, great efforts must be made to study considering representative coastal aquifer types, climatic conditions and environmental dynamics, and to promote cooperation among experts in related disciplines. We believe that the intersection and fusion of various disciplines will have a profound impact on SGD research, and can better understand the interaction process of seawater and groundwater, which is of great significance for the study of the hydrologic cycle in the Yellow Sea and Bohai Sea region

\section{References}

Adolf, J.E.; Burns, J.; Walker, J.K., and Gamiao, S., 2019. Near shore distributions of phytoplankton and bacteria in relation to submarine groundwater discharge-fed fishponds, Kona coast, Hawai'i, USA. Estuarine Coastal and Shelf Science, 219, 341-353.

Alorda-Kleinglass, A.; Garcia-Orellana, J.; Rodellas, V.; Cerda-Domenech, M.; Tovar-Sanchez, A.; DiegoFeliu, M.; Trezzi, G.; Sanchez-Quilez, D.; Sanchez-Vidal, A., and Canals, M., 2019. Remobilization of dissolved metals from a coastal mine tailing deposit driven by groundwater discharge and porewater exchange. Science of the Total Environment, 688, 1359-1372.

Burnett W.C.; Bokuniewicz, H.; Huettel, M.; Moore, W.S., and Taniguchi, M., 2003. Groundwater and pore water inputs to the coastal zone. Biogeochemistry, 66(1 /2), 3-33. 
Burnett, K.M.; Wada, C.A.; Taniguchi, M.; Sugimoto, R., and Tahara, D., 2018. Evaluating the tradeoffs between groundwater pumping for snow-melting and nearshore fishery productivity in obama city, Japan. Water, 10(11), 1556. DOI: 10.3390/w10111556

Burnett, W.C.; Taniguchi, M., and Oberdorfer, J., 2001. Measurement and significance of the direct discharge of groundwater into the coastal zone. Journal of Sea Research, 46, 109-116.

Cable, J.E.; Burnett W C.; Chanton, J.P.; Corbett, D.R., and Cable, P.H.,1997. Field evaluation of seepage meters in the coastal marine environment. Estuarine, Coastal and Shelf Science, 45, 367-375.

Cen, R.R.; Liu, Y.N.; Xing, N.; Chen, M.; Cheng, H., and Cai, Y.H., 2017. Sources and conservative mixing of uranium in the Taiwan Strait. Acta Oceanologica Sinica, 36(3), 72-81.

Chang, Y.W.; Hu, X.N.; Zhang, H.X., and Chen, L, 2018. Quantifying seawater-groundwater exchange rates in muddy tidal flat: a case study of the south coast of the Laizhou Bay. Marine Science Bulletin, 37(4), 450-458. (in Chinese)

Charette, M.A.; Moran, S.B.; Pike, S.M., and Smith, J.N., 2001. Investigating the carbon cycle in the Gulf of Maine using the natural tracer thorium 234. Journal Of Geophysical Research-Oceans, 106(C6), 11553-11579.

Cho, H.M.; Kim, G., and Shin, K.H., 2019. Tracing nitrogen sources fueling coastal green tides off a volcanic island using radon and nitrogen isotopic tracers. Science of the Total Environment, 665, 913-919.

da R.; Cacinele M.; Barboza; Eduardo, G.; Niencheski, L., and Felipe, H., 2018. Radon activity and submarine groundwater discharge in different geological regions of a coastal barrier in Southern Brazil. Environmental Earth Sciences, 77(14), 527. DOI: 10.1007/s12665-018-7711-0

Dias, T.H.; de O.; J.; Sanders, C.J.; Carvalho, F.; Sanders, L.M.; Machado, E.C., and Sa, F., 2016. Radium isotope (Ra-223, Ra-224, Ra-226 and Ra-228) distribution near Brazil's largest port, Paranagua Bay, Brazil. Marine Pollution Bulletin, 111(1/2), 443-448.

Dimova, N.T.; Swarzenski, P.W.; Dulaiova, H., and Glenn, C.R., 2012. Utilizing multichannel electrical resistivity methods to examine the dynamics of the fresh water-seawater interface in two Hawaiian groundwater systems, Journal Of Geophysical Research-Oceans, 117, C02012. DOI: 10.1029/2011JC007509.

Donis, D.; Janssen, F.; Liu, B.; Wenzhofer, F.; Dellwig, O.; Escher, P.; Spitzy, A., and Bottcher, M.E., 2017. Biogeochemical impact of submarine ground water discharge on coastal surface sands of the southern Baltic Sea. Estuarine, Coastal and Shelf Science, 189, 131-142.

Dzhamalov, R.G, and Safronova, T.I, 2002. On estimating chemical discharge into the world ocean with groundwater. Water Resources, 29(6), 626-631

Franz, M.; Lieberum, C.; Bock, G., and Karez, R., 2019. Environmental parameters of shallow water habitats in the SW Baltic Sea. Earth System Science Data, 11(3), 947-957.

Guo, X.Y.; Xu, B.C.; Yu, Z.G.; Li, X.Q.; Nan, H.M.; Jian, H.M.; Jiang, X.Y.; Diao, S.B., and Gao, M.S., 2017. Radium isotopes assess water mixing processes and its application in the Zhujiang River estuary. Chinese Journal of Oceanology and Limnology, 35, 1108-1116.

Henderson, R.D.; Day-Lewis, F.D.; Abarca, E.; Harvey, C.F.; Karam, H.N.; Liu, L.B., and Lane, J.W., 2010. Marine electrical resistivity imaging of submarine groundwater discharge: sensitivity analysis and application in Waquoit Bay, Massachusetts, USA. Hydrogeology Journal, 18(1), 173-185.

Hou, L.J.; Li, H.L.; Zheng, C.M.; Ma, Q.; Wang, C.Y.; Wang, X.J., and Qu, WJ., 2016. Seawatergroundwater Exchange in a Silty Tidal Flat in the South Coast of Laizhou Bay, China. Journal of Coastal Research, 74, 136-148. DOI: 10. 2112 / SI74-013. 
Hwang, D.W.; Kim, G.; Lee, W.C., and Oh, H.T., 2010. The role of submarine groundwater discharge (SGD) in nutrient budgets of Gamak Bay, a shellfish farming bay, in Korea. Journal of Sea Research, 64(3), 224-230.

Johnson, C.D.; Swarzenski, P.W.; Richardson, C.M.; Smith, C.G.; Kroeger, K.D., and Ganguli, P.M, 2015. Ground-truthing Electrical Resistivity Methods in Support of Submarine Groundwater Discharge Studies: Examples from Hawaii, Washington, and California. Journal of Environmental And Engineering Geophysics, 20(1), 81-87.

Kang, K.M.; Kim, D.J.; Kim, Y.; Lee, E.; Kim, B.G.; Kim, S.H.; Ha, K.; Koh, D.C.; Cho, Y.K., and Kim, G., 2019. Quantitative estimation of submarine groundwater discharge using airborne thermal infrared data acquired at two different tidal heights. Hydrological Processes, 33, 1089-1100.

Kelly, J.L.; Dulai, H.; Glenn, C.R., and Lucey, P.G., 2019. Integration of aerial infrared thermography and in situ radon-222 to investigate submarine groundwater discharge to Pearl Harbor, Hawaii, USA. Limnology and Oceanography, 64(1), 238-257.

Kim, G.; Ryu, J.W.; Yang, H.S., and Yun, S.T., 2005. Submarine groundwater discharge (SGD) into the Yellow Sea revealed by Ra-228 and Ra-226 isotopes: Implications for global silicate fluxes. Earth and Planetary Science Letters, 237(1/2), 156-166.

Kohout, F.A, 1966. Submarine springs: A neglected phenomenon of coastal hydrology. Hydrology, 26, 391-413.

Krall, L.; Trezzi, G.; Garcia, O.J.; Rodellas, V.; Morth, C.M., and Andersson, P., 2017. Submarine groundwater discharge at Forsmark, Gulf of Bothnia, provided by Ra isotopes. Marine Chemistry, 196, 162-172.

Lamontagne, S. and Webster, I.T., 2019. Theoretical Assessment of the Effect of Vertical Dispersivity on Coastal Seawater Radium Distribution. Frontiers in Marine Science, 6,357. DOI: 10.3389/fmars.2019.00357.

Lee, B.J.; Lee, J.H., and Kim, D.H., 2018. An alternative approach to conventional seepage meters: Buoytype seepage meter. Limnology and Oceanography, 16(5), 299-308.

Lee, D.R, 1977. A device for measuring seepage flux in lakes and estuaries. Limnology and Oceanography, $22,140-147$.

Li, H.L. and Jiao, J.J., 2013. Quantifying tidal contribution to submarine groundwater discharges: A review. Chinese Science Bulletin, 58(25), 3053-3059.

Li, N.; Guo, X.J.; Ma, Q.W., and Zhang, Y.F., 2019. The research of electrical resistivity system's application effect simulation in coastal submarine confined groundwater discharge. Acta Oceanologica Sinica, 41(5), 128137.(in Chinese)

Li, X.Y.; Dong, N.; Zhang, L.; Xiao, G.Q.; Wang, H.P. and Jiang, X.Y, 2019. Radium isotopes distribution and submarine groundwater discharge in the Bohai Sea. Groundwater for Sustainable Development, 9. DOI:10.1016/j.gsd.2019.100242.

Liu, H.T.; Guo, Z.R.; Gao, A.G.; Yuan, X.J., and Zhang, B., 2016. O-18 and Ra-226 in the Minjiang River estuary, China and their hydrological implications. Estuarine Coastal and Shelf Science, 173, 93-101.

Liu, J.A.; Du, J.Z., and Yi, L.X., 2017. Ra Tracer-Based Study of Submarine Groundwater Discharge and Associated Nutrient Fluxes into the Bohai Sea, China: A Highly Human-Affected Marginal Sea. Journal of Geophysical Research-Oceans, 122(11), 8646-8660.

Liu, J.A.; Du, J.Z.; Wu, Y., and Liu, S.M., 2018. Nutrient input through submarine groundwater discharge in two major Chinese estuaries: the Pearl River Estuary and the Changjiang River Estuary. Eatuarine Coastal and Shelf Science, 203, 17-28. 
Liu, J.A.; Su, N.; Wang, X.L., and Du, J.Z., 2017. Submarine groundwater discharge and associated nutrient fluxes into the Southern Yellow Sea: A case study for semi-enclosed and oligotrophic seas-implication for green tide bloom. Journal of Geophysical Research-Oceans, 122(1), 139-152.

Liu, Y.; Jiao, J.J., and Cheng, H.K., 2018. Tracing submarine groundwater discharge flux in Tolo Harbor, Hong Kong (China). Hydrogeology Journal, 26(6), 1857-1873.

Ma, Q.; Li, H.L.; Wang, X.J.; Wang, C.Y.; Wan, L.; Wang, X.S., and Jiang, X.W., 2015. Estimation of seawater-groundwater exchange rate: case study in a tidal flat with a large-scale seepage face (Laizhou Bay, China). Hydrogeology Journal, 23, 265-275.

Maher, D.T.; Call, M.; Macklin, P.; Webb, J.R., and Santos, I.R., 2019. Hydrological Versus Biological Drivers of Nutrient and Carbon Dioxide Dynamics in a Coastal Lagoon. Estuaries and Coasts, 42, 10151031.

Moore, W.S, 1996. Large groundwater inputs to coastal waters revealed by Ra-226 enrichments. Nature, $380(6575), 612-614$.

Moore, W.S, 2010. The effect of submarine groundwater discharge on the ocean. The Annual Review of Marine Science, 2, 59-88.

Moore, W.S. Seasonal distribution and flux of radium isotopes on the southeastern US continental shelf, 2007. Journal of Geophysical Research - Oceans, 112, C10. DOI: 10.1029/2007JC004199.

Niencheskil, L.F.H., and Windom, H.L., 2015. Chemistry of a Surficial Aquifer of a Large Coastal Lagoon Barrier and its Relation to Adjacent Surface Waters of Brazil. Journal of Coastal Research, 31(6), 1417-1428.

Nikpeyman, Y.; Hosono, T.; Ono, M.; Yang, H.; Ichiyanagi, K.; Shimada, J., and Takikawa, K., 2019. Sea surficial waves as a driving force that enhances the fresh shallow coastal groundwater flux into the oceans. Environmental Earth Sciences, 78(8), 252. DOI: 10.1007/s12665-019-8258-4.

Oberdorfer, J.A, 2003. Hydrogeologic modeling of submarine groundwater discharge: Comparison to other quantitative methods. Biogeochemistry, 66(1-2), 159-169.

Oehler, T.; Tamborski, J.; Rahman, S.; Moosdorf, N.; Ahrens, J.; Mori, C.; Neuholz, R.; Schnetger, B., and Beck, M., 2019. DSi as a Tracer for Submarine Groundwater Discharge. Frontiers in Marine Science, 6, 563. DOI: 10.3389/fmars.2019.00563.

Paulsen, R.J.; Smith, C.F.; O'Rourke, D., and Wong, T.F., 2001. Development and evaluation of an ultrasonic ground water seepage meter. Groundwater, 39(6), 904-911.

Qu, W.J.; Li, H.L.; Huang, H.; Zheng, C.M.; Wang, C.Y.; Wang, X.J., and Zhang, Y., 2017. Seawatergroundwater exchange and nutrients carried by submarine groundwater discharge in different types of wetlands at Jiaozhou Bay,China. Journal of Hydrology, 555, 185-197.

Robinson, C.; Li, L., and Barry, D.A., 2007. Effect of tidal forcing on a subterranean estuary. Advances in Water Resources, 30(4), 851-865.

Sadat, N.M. and Glamore, W., 2019. Porewater exchange drives trace metal, dissolved organic carbon and total dissolved nitrogen export from a temperate mangrove wetland. Journal of Environmental Management, 248, UNSP 109264. DOI: 10.1016/j.jenvman.2019.109264

Santos, I. R.; Eyre, B.D., and Huettel, M., 2012. The driving forces of porewater and groundwater flow in permeable coastal sediments: A review. Estuarine, Coastal and Shelf Science, 98, 1-15.

Sholkovitz, E.; Herbold, C., and Charette, M., 2003. An automated dye-dilution based seepage meter for the time-series measurement of submarine groundwater discharge. Limnology and Oceanography, 1, 16-28.

Slomp, C.P. and Van, C.P., 2004. Nutrient inputs to the coastal ocean through submarine groundwater discharge: controls and potential impact. Journal Of Hydrology, 295(1-4), 64-86. 
Swarzenski, P.W.; Reich, C.; Kroeger K.D., and Baskaran, M., 2007. Ra and Rn isotopes as natural tracers of submarine groundwater discharge in Tampa Bay, Florida. Marine Chemistry, 104 (1/2), 69-84.

Tamborski, J.; Bejannin, S.; Garcia-Orellana, J.; Souhaut, M.; Charbonnier, C.; Anschutz, P.; Pujo-Pay, M.; Conan, P.; Crispi, O.; Monnin, C.; Stieglitz, T.; Rodellas, V.; Andrisoa, A.; Claude, C., and Van, B.P., 2018. A comparison between water circulation and terrestrially-driven dissolved silica fluxes to the Mediterranean Sea traced using radium isotopes. Geochimica et Cosmochimica Acta, 238, 496-515.

Tamborski, J.; Van, B.P.; Rodellas, V.; Monnin, C.; Bergsma, E.; Stieglitz, T.; Heilbrun, C.; Cochran, J.K.; Charbonnier, C.; Anschutz, P.; Bejannin, S., and Beck, A., 2019. Temporal variability of lagoon-sea water exchange and seawater circulation through a Mediterranean barrier beach. Limnology and Oceanography, 64(5), 2059-2080.

Taniguchi, M.; Burnett, W.C.; Smith, C.F.; Paulsen, R.J.; O'Rourke, D.; Krupa, S.L., and Christoff, J.L., 2003. Spatial and temporal distributions of submarine groundwater discharge rates obtained from various types of seepage meters at a site in the Northeastern Gulf of Mexico. Biogeochemistry, 66(1/2), 35-53.

Taniguchi, M.; Ishitobi, T.; Chen, J.Y. ; Onodera, S.I.; Miyaoka, K. ; Burnett, W.C.; Peterson, R.; Liu, G.Q., and Fukushima, Y., 2008. Submarine groundwater discharge from the Yellow River Delta to the Bohai Sea, China. Journal of Geophysical Research-oceans, 113, C06025, doi:10.1029/2007JC004498.

Wang, B.; Guo, Z.R.; Yuan, X.J.; Zhang, B.; Ma, Z.Y., and Liu, J., 2014. Distribution characteristics of radium isotopes and their influence factors in the water of Jiaozhou Bay area. Nuclear Techniques, 37(3), 030206-1-030206-9.(in Chinese)

Wang, X.J.; Li, H.L.; Jiao, J.J.; Barry, D.A.; Li, L.; Luo, X.; Wang, C.Y.; Wan, L.; Wang, X.S.; Jiang, X.W.; Ma, Q., and Qu, W.J., 2015. Submarine fresh groundwater discharge into Laizhou Bay comparable to the Yellow River flux. Scientific Reports, 5, 8814. DOI: 10.1038/srep08814.

Wang, X.J.; Li, H.L.; Zhang, Y.; Qu, W.J., and Schubert, M., 2019. Submarine groundwater discharge revealed by Rn-222: comparison of two continuous on-site Rn-222-in-water measurement methods. Hydrogeology Journal, 27, (5), 1879-1887.

Wang, X.L. And Du, J.Z., 2016. Submarine groundwater discharge into typical tropical lagoons: A case study in eastern Hainan Island, China. Geochemistry Geophysics Geosystems, 17(11), 4366-4382.

Xia, D.; Yu, Z.G.; Xu, B.C.; Gao, M.S.; Mi, T.Z.; Jiang, X.Y., and Yao, P., 2016. Variations of Hydrodynamics and Submarine Groundwater Discharge in the Yellow River Estuary Under the Influence of the Water-Sediment Regulation Scheme. Estuaries and Coasts, 39(2), 333-343.

Xing, Q.G.; Braga, F.; Tosi, L.; Lou, M.J.; Zaggia, L.; Teatini, P.; Gao, X.L.; Yu, L.J.; Wen, X.H., and Shi, P., 2016. Detection of Low Salinity Groundwater Seeping into the Eastern Laizhou Bay (China) with the Aid of Landsat Thermal Data. Journal of Coastal Research, 74, 149-156. DOI: 10. 2112 / SI74 -014.

Xu, B.C.; Burnett, W.; Dimova, N.; Diao, S.B., and Mi, T.Z., 2013. Hydrodynamics in the Yellow River Estuary via radium isotopes: Ecological perspectives. Continental Shelf Research, 66, 19-28.

Xu, B.C.; Xia, D.; Burnett, W.C.; Dimova, N.T.; Wang, H.J.; Zhang, L.J.; Gao, M.S. ; Jiang, X.Y., and Yu, Z.G., 2014. Natural Rn-222 and Rn-220 indicate the impact of the Water-Sediment Regulation Scheme (WSRS) on submarine groundwater discharge in the Yellow River estuary, China. Applied Geochemistry, 51, 79-85.

Yang, D.F.; Miao, Z.Q.; Xu, H.Z.; Chen, Y. And Sun, J.Y., 2014. Jiaozhou Bay water exchange time. Marine Environmental Science, 32(3), 373-380.(in Chinese)

Yu, X.Y.; Xin, P.; Wang, S.S.J.; Shen, C.J., and Li, L., 2019. Effects of multi-constituent tides on a subterranean estuary. Advances in Water Resources, 124, 53-67. 
Yuan, X.J.; Guo, Z.R.; Huang, L.; Zhang, B.; Ma, Z.Y., and Liu J., 2016. Estimating Submarine Groundwater Discharge into the Jiaozhou Bay Using (226)Ra. Journal of Jilin University. Earth Science Edition, 46(5), 1490-1500. (in Chinese)

Zarnoch, C.B.; Hoellein, T.J.; Furman, B.T., and Peterson, B.J., 2017. Eelgrass meadows, \&ITZostera marina\&IT (L.), facilitate the ecosystem service of nitrogen removal during simulated nutrient pulses in Shinnecock Bay, New York, USA. Marine Pollution Bulletin, 124(1), 376-387.

Zhang, Y.; Li, H.L.; Wang, X.J.; Zheng, C.M.; Wang, C.Y.; Xiao, K.; Wan, L.; Wang, X.S.; Jiang, X.W, and .Guo, H.M., 2016. Estimation of submarine groundwater discharge and associated nutrient fluxes in eastern Laizhou Bay, China using Rn-222. Journal of Hydrology, 533, 103-113.

Zhu, A.P.; Saito, M.; Onodera, S.; Shimizu, Y.; Jin, G.Z.; Ohta, T., and Chen, JY., 2019. Evaluation of the spatial distribution of submarine groundwater discharge in a small island scale using the Rn-222 tracer method and comparative modeling. Marine Chemistry, 209, 25-35.

Table. The representative studies on SGD in Huanghai and Bohai

\begin{tabular}{|c|c|c|c|c|c|}
\hline Region & Area & $\begin{array}{l}\text { SGD outflow } \\
\left(\mathrm{m}^{2} \cdot \text { day }^{-1}\right)\end{array}$ & $\begin{array}{l}\text { SGD inflow } \\
\left(m^{2} \cdot \text { day }^{-1}\right)\end{array}$ & $\begin{array}{l}\text { SGD flux } \\
\left(m^{3} \cdot \text { day }^{-1}\right)\end{array}$ & Referance \\
\hline $\begin{array}{l}\text { Xinzhuang } \\
\text { Village }\end{array}$ & $\begin{array}{l}\text { eastern coast } \\
\text { of Laizhou Bay }\end{array}$ & & & $6.93^{*} 10^{6}$ & Yan Zhang \\
\hline $\begin{array}{l}\text { Haimiao } \\
\text { Village }\end{array}$ & $\begin{array}{l}\text { northwestern } \\
\text { coast of } \\
\text { Laizhou Bay }\end{array}$ & 15.3 & 8.8 & & Qian Ma \\
\hline $\begin{array}{l}\text { Qingxiang } \\
\text { Town }\end{array}$ & $\begin{array}{l}\text { southern coast } \\
\text { of Laizhou Bay }\end{array}$ & 164 & 6.5 & & Lijia Hou \\
\hline Changyi & southern coast & & 80.4 & & Zhang \\
\hline City & of Laizhou Bay & & & & Hanxiong \\
\hline $\begin{array}{l}\text { Changyi } \\
\text { City }\end{array}$ & $\begin{array}{l}\text { southern coast } \\
\text { of Laizhou Bay }\end{array}$ & 17.46 & 2.71 & & Chang Yawen \\
\hline Licun River & Jiaozhou Bay & & & $1.62^{*} 10^{7}$ & Yan Zhang \\
\hline $\begin{array}{l}\text { Yang River } \\
\text { et al. }\end{array}$ & Jiaozhou Bay & & & $6.3^{*} 10^{6}$ & Yuan Xiaojie \\
\hline $\begin{array}{l}\text { the whole } \\
\text { Bohai Sea }\end{array}$ & Bohai Bay & & & $2.84 \times 10^{7}$ & Lixin Yi \\
\hline $\begin{array}{l}\text { the coast of } \\
\text { Bohai Sea }\end{array}$ & Bohai Bay & & & $(5.48 \pm 3.56) * 10^{8}$ & Jianan Liu \\
\hline Changjiang & Southern & & & $(3.56 \pm 2.38) * 10^{9}$ & Jianan Liu \\
\hline Rivermouth & Yellow Sea & & & & \\
\hline $\begin{array}{l}\text { Yellow River } \\
\text { Estuary }\end{array}$ & Bohai & & & $1.3^{*} 10^{9}$ & Bochao Xu \\
\hline $\begin{array}{l}\text { Yellow River } \\
\text { Estuary }\end{array}$ & Bohai & & & $6.1-9.0 \times 10^{8}$ & Yan Zhan \\
\hline
\end{tabular}

Figure Legends

Figure 1. The area of Huanghai and Bohai, which consists of Liaoning, Tianjin, Shandong and Jiangsu Province

Figure 2. Schematic diagram of submarine groundwater discharge

Figure 3. The model of manual percolation instrument 

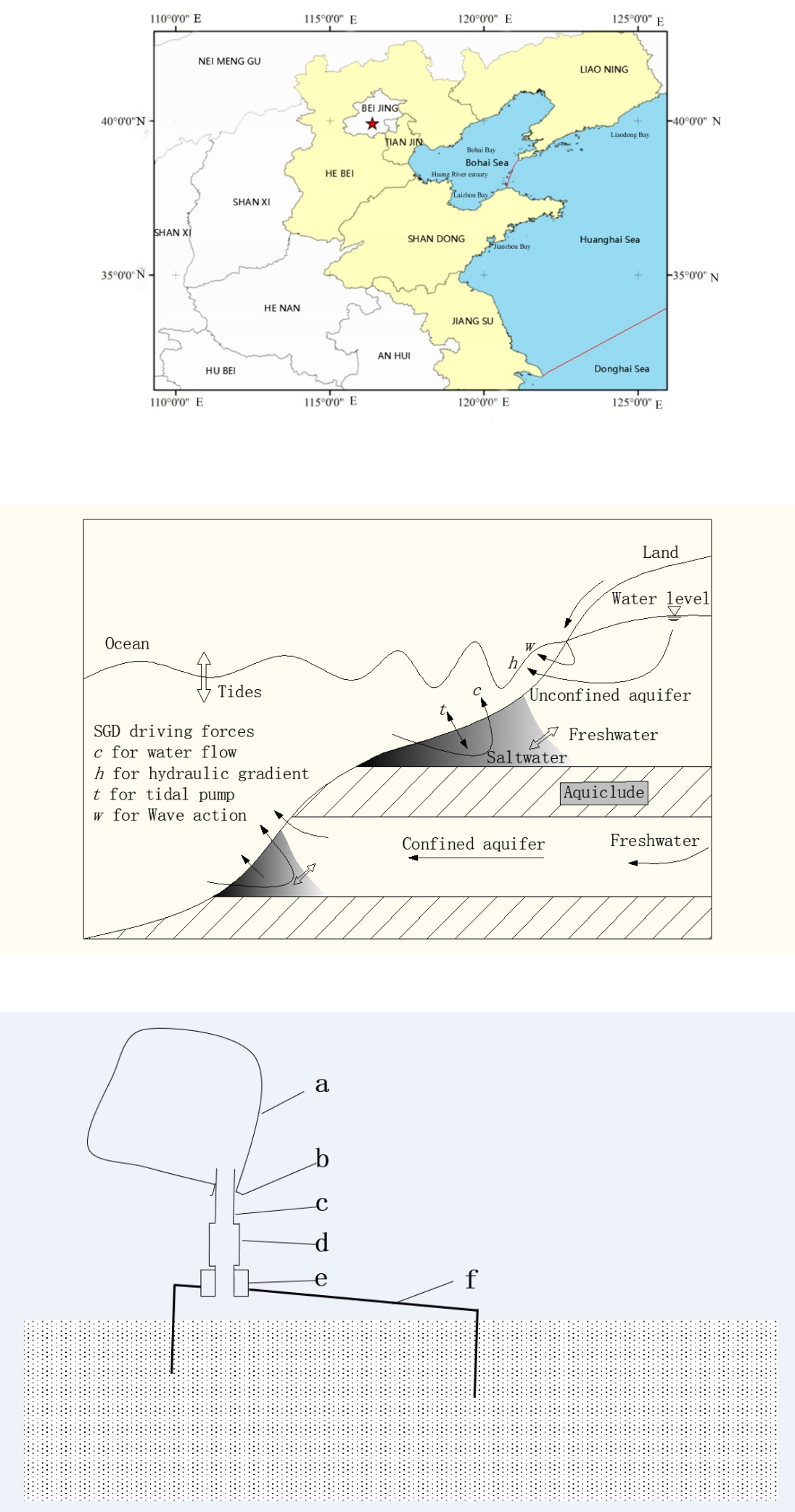

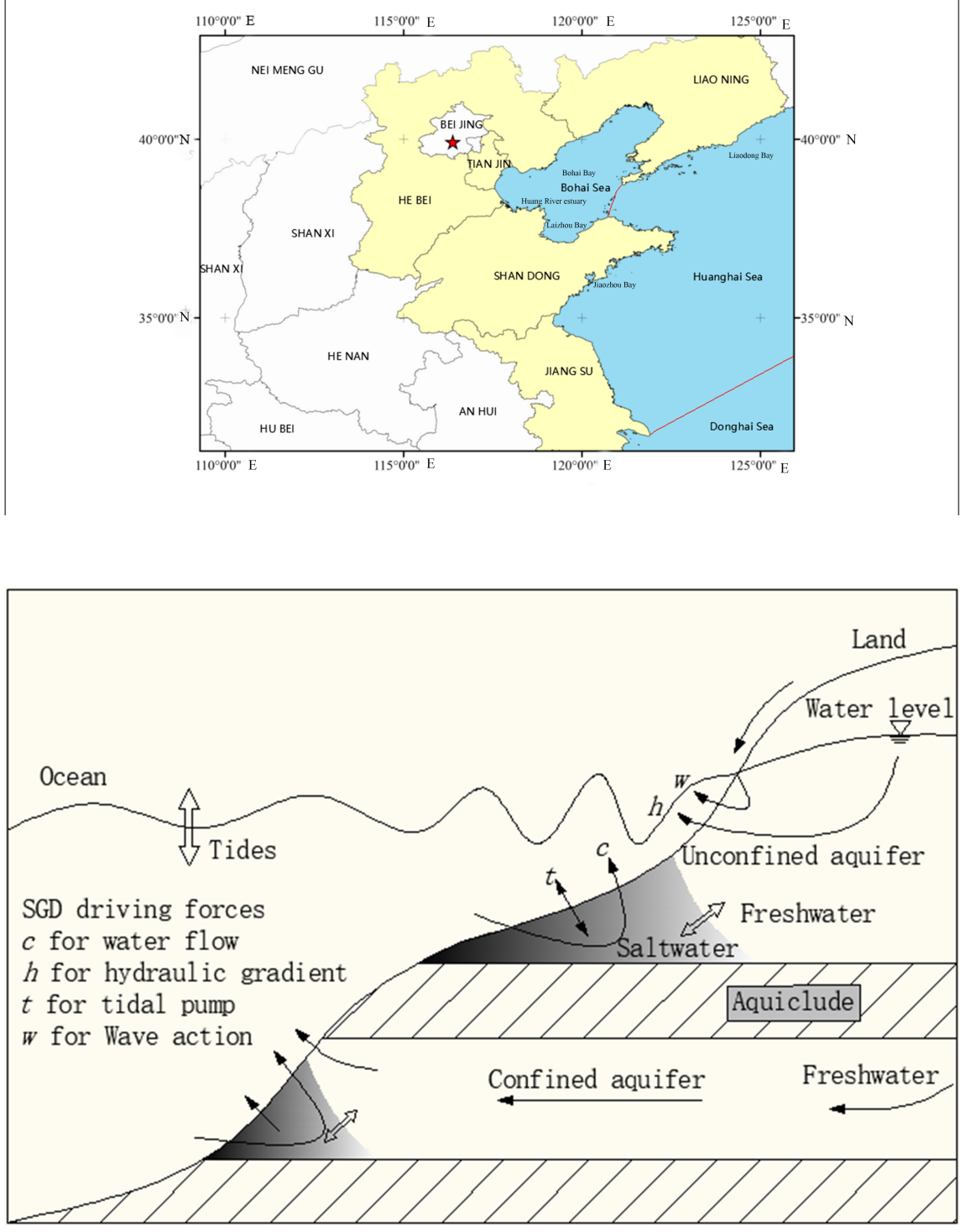


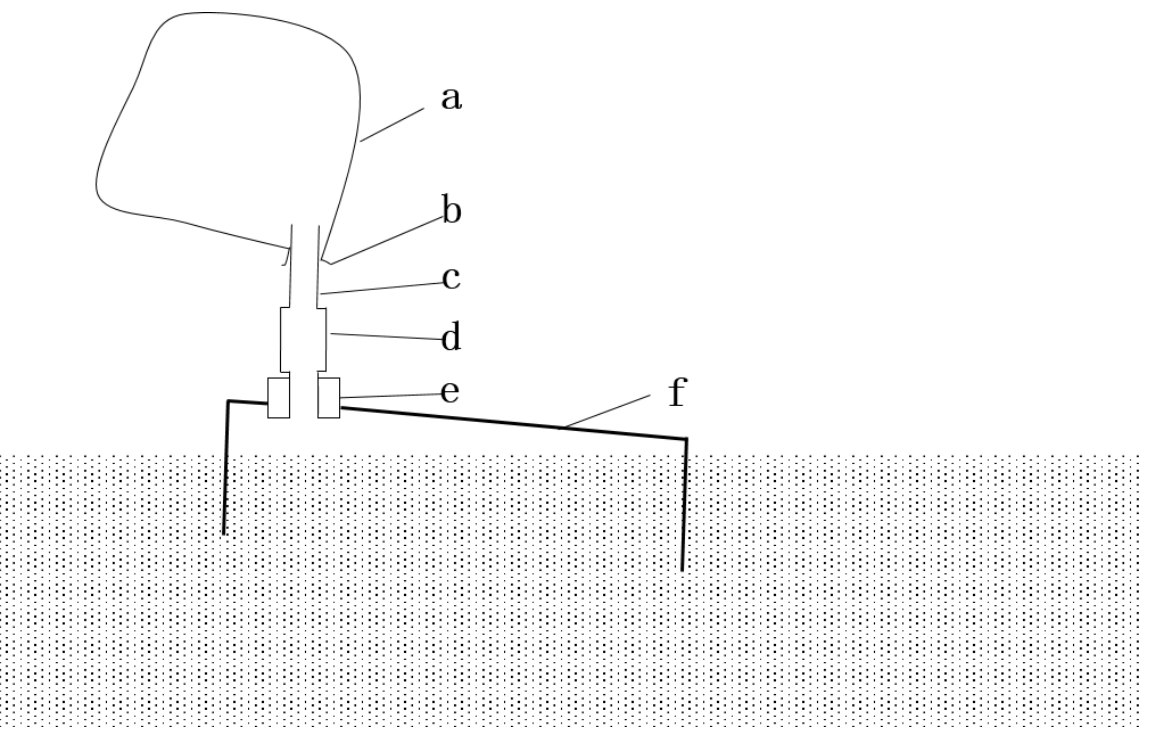

